\title{
O conhecimento em sala de aula: a organização do ensino numa perspectiva interdisciplinar
}

\section{Knowledge in the classroom: teaching organization in an interdisciplinary perspective}

\author{
Maria Antonia Ramos de Azevedo* \\ Maria de Fátima Ramos de Andrade**
}

\begin{abstract}
RESUMO
Este trabalho é uma pesquisa bibliográfica sobre a interdisciplinaridade e sua organização na dinâmica curricular. Apresentamos a conceituação da interdisciplinaridade e propomos encaminhamentos epistêmicometodológicos para a implementação da prática interdisciplinar na realidade escolar. Como conclusão destaca-se que a interdisciplinaridade possibilita que a escola se torne um lugar onde se produza de forma coletiva e crítica o conhecimento escolar, exigindo a restruturação curricular e a formação continuada dos professores. É necessária a planificação e a operacionalização dos conhecimentos escolares na matriz curricular por meio de uma dimensão vertical, que implica a idéia de profundidade e complexidade crescente dos conteúdos, e uma dimensão horizontal, que estabelece a interação dos conhecimentos com as outras áreas/disciplinas. A idéia da implementação de práticas interdisciplinares deve desenhar, tecer, alinhavar a verticalidade e a horizontalidade da matriz curricular, para que os professores tenham claras as interfaces das disciplinas e as possíveis inter-relações, criando, a partir disso, novos conhecimentos de forma relacional e contextual.

Palavras-chave: interdisciplinaridade; teoria de ensino; matriz curricular.

* Doutoranda FE/USP. Professora Unifra-RS.

** Doutoranda PUC/SP. Professora Campos Salles-SP.
\end{abstract}


AZEVEDO, M. A. R.; ANDRADE, M. F. R. O conhecimento em sala de aula: a organização do ensino numa perspectiva interdisciplinar

\begin{abstract}
This paper is a bibliographic research about interdisciplinarity and its organization in the curriculum. The concept of interdisciplinarity is discussed and a few epistemologic-methodological approaches are proposed to introduce the interdisciplinary practice in the school routine. As a conclusion, it is emphasized that interdisciplinarity should be taken as an instrument that may allow school to be an environment where critical and collective knowledge may be produced. To such end, curriculum should be redesigned and continuing teacher education practiced. It is needed, on one hand, to plan and operate knowledge vertically through the curriculum matrix, relating the idea of increasing complexity and deepening (vertical dimension), and in the other hand to relate the knowledge of one discipline to another (horizontal dimension). The idea of interdisciplinarity should delicately bring together the vertical and horizontal dimensions through curriculum and teacher practice, to allow the emergence of new knowledge with relational and contextual meaning.
\end{abstract}

Key-words: interdisciplinary; teaching; curriculum theory.

\title{
Introdução
}

Os cursos de formação de professores sofrem críticas referentes à baixa qualidade da formação oferecida, o distanciamento entre a teoria e a prática social que leva à própria desvalorização do "ser professor" no mundo pósmoderno.

É notória a presença, ainda, nos cursos de formação de professores, de uma prática muito mais voltada para a disciplinaridade no dia-a-dia dos cursos, apesar de discutirem o valor e a importância da interdisciplinaridade como componente essencial para a formação de professores para a Educação Básica, para que os professores possam se tornar mais competentes, críticos, criativos e reflexivos.

Entretanto, na prática da sala de aula, os professores formadores não conseguem estabelecer ambientes de ensino e aprendizagem interdisciplinares, mesmo que a matriz curricular e as práticas de ensino propiciem aberturas para que essas práticas aconteçam de fato na formação de professores. 
Não podemos desconsiderar que existem algumas experiências significativas que buscam repensar a formação de seus alunos e também dos próprios formadores, a maior integração entre a teoria e a prática, o redimensionamento dos estágios na matriz curricular (Diretrizes Curriculares Nacionais) e a valorização da formação continuada dos profissionais de ensino.

É notória a necessidade de um maior aprofundamento desta temática, buscando, nas entrelinhas da epistemologia da interdisciplinaridade, as respostas e/ou caminhos a serem percorridos a fim de um pleno envolvimento dos sujeitos no processo educacional, sob a fecunda idéia de interação dos conhecimentos nas mais diversas áreas de atuação e estudos.

\section{Metodologia}

Esta pesquisa de cunho bibliográfico busca analisar e estudar encaminhamentos epistêmicos e metodológicos para a real implementação da prática interdisciplinar, por meio do desenvolvimento de uma pesquisa qualitativa, analisando textos e documentos que tratam a questão da interdisciplinaridade sob a ótica de diversos autores nacionais e internacionais, com o intuito de desmistificar as questões relacionadas a esse pleito. Para isso, contextualiza o tema e, sobretudo, direciona o foco de observação na formação de professores sob a organização interdisciplinar, para obter mudanças de ordem educacional, em prol de uma maior e melhor qualificação docente e discente.

Utilizamos uma pesquisa bibliográfica, pois, segundo Manzo (1971, p. 32), "[...] a bibliografia pertinente oferece meios para definir, resolver, não somente problemas já conhecidos, como também explorar novas áreas nas quais os problemas não se cristalizaram suficientemente".

Sentimos, então, a necessidade de trabalhar esse tema por meio de pesquisa bibliográfica, por percebermos que há ainda muitas controvérsias teórico-práticas sobre a interdisciplinaridade, dificultando um real entendimento de práticas interdisciplinares no interior das realidades escolares, como também nos próprios cursos de formação de professores. 


\section{A interdisciplinaridade e o papel das atividades de ensino}

A interdisciplinaridade tem como proposta promover uma nova forma de trabalhar o conhecimento, na qual haja interação entre sujeitos-sociedadeconhecimentos na relação professor-aluno, professor-professor e aluno-aluno, de maneira que o ambiente escolar seja dinâmico e vivo e os conteúdos e/ou temas geradores sejam problematizados e vislumbrados juntamente com as outras disciplinas.

A interdisciplinaridade é o elo de ligação entre os profissionais do ensino, como forma de reciprocidade, de reflexão mútua, em substituição à concepção fragmentária do conhecimento, fazendo com que estes agentes do ensino tenham uma atitude diferenciada perante os obstáculos educacionais.

Percebe-se, então, que a interdisciplinaridade exige uma atitude de abertura e responsabilidade. Tanto Schon (1983) como Fazenda (1993) consideram que o professor necessita desenvolver uma ação permeada de criticidade e reflexão perante o aluno, o conhecimento, a realidade e o outro, estando disposto a vivenciar a dialogicidade que, segundo Freire (1996), entrelaça as ações de saber ouvir, falar, enxergar, calar, interagir pela via da comunicação, do diálogo e da troca mútua.

Neste sentido, a interdisciplinaridade resgata a importância do "outro", sem o qual não pode haver a troca mútua da evolução do pensamento e da linguagem, e amplia os horizontes dentro do processo sócio-histórico educacional, resgatando a importância do conhecimento das potencilidades, dos limites, das diferenças e do processo criativo de cada ciência, respeitando-se, assim, a relatividade entre elas.

Há, pois, a transformação de um pensamento lógico formal em um pensamento não-linear configurado como dialético, porque não pressupõe a unificação de diferentes saberes, mas a construção incessante de relações entre si.

Dentro desse âmbito de observação é cabível perceber que a prática da interdisciplinaridade está inteiramente relacionada à pesquisa, conforme podemos observar na seguinte citação:

O professor, na perspectiva da interdisciplinaridade, não é um mero repassador de conhecimentos, mas é reconstrutor juntamente com seus alunos; o professor é, conseqüentemente, um pesquisador que 
possibilita aos alunos, também, a prática da pesquisa. A problematização como metodologia para a reconstrução de construtos dá condições ao aluno de mover-se no âmbito das teorias, das diferentes áreas do saber, construindo a teia de relações que vai torná-lo autônomo diante da autoridade do saber. O professor pesquisador constitui-se, portanto, em agente necessário de uma formação calçada na interdisciplinaridade (TomazeTti, 1998, p. 13).

A perspectiva epistemológica da interdisciplinaridade não pressupõe unicamente a integração, mas a interação das disciplinas, de seus conceitos e diretrizes, de sua metodologia, de seus procedimentos, suas informações na organização do ensino, enfim, traz a idéia da não globalização dos conteúdos simplesmente, mas, sobretudo, de trabalhar as diferenças, criando a partir disso novos caminhos epistêmicos e metodológicos como forma de compreender e enriquecer conhecimentos sobre as mais diversas áreas do saber.

A interdisciplinaridade é o elo que possibilita o estabelecimento de inúmeras relações das disciplinas com a realidade, num processo recíproco de aprendizagens múltiplas e intermináveis. Assim, professor e aluno deverão estabelecer diferentes interconexões entre a epistemologia dos conhecimentos e o mundo que os cerca, a fim de exercitar cotidianamente seus saberes e as relações entre teoria e prática.

Percebe-se que todo o processo interdisciplinar deve estar pautado na reflexão, o que podemos observar inclusive nas concepções de Schon (1983), que retrata a importância do conhecimento na ação, da reflexão na ação e da reflexão sobre a ação permeando as situações educativas.

O processo reflexivo torna-se alicerce para que se construa um processo interdisciplinar efetivo no cotidiano, por meio de uma prática pedagógica que esteja impregnada de pesquisa, discussão, análise e desenvolvimento metacognitivo dos professores e alunos sobre o conhecimento construído de forma individual e coletiva.

É um processo de desestruturação situacional do prévio, do possuído e do conhecido, para buscar uma nova estruturação do pensamento. É necessária a passagem do pensamento linear lógico-formal para o pensamento dialético, em que se efetivem:

- $\quad$ as contradições dos fenômenos;

- $\quad$ as relações múltiplas dos saberes; 
AZEVEDO, M. A. R.; ANDRADE, M. F. R. O conhecimento em sala de aula: a organização do ensino numa perspectiva interdisciplinar

- $\quad$ a problematização da rivalidade;

- a busca pela integração do pensar + fazer e/ou fazer + pensar;

- o processo contínuo de ação - reflexão - ação;

- $\quad$ a superação da dependência, da passividade e da rivalidade;

- a autonomia, a ação reflexiva e a cooperação.

Quando refletimos sobre o papel e a importância do trabalho interdisciplinar na Escola Básica, é preciso pensar a organização do ensino, pois a forma como o conhecimento é adquirido, refletido e organizado dentro da matriz curricular retrata a própria concepção de ensino e aprendizagem.

Assim, o estudo do currículo acaba por envolver uma análise micro e macro da realidade escolar, sendo um processo aberto que movimenta a própria realidade educativa.

Infelizmente, a idéia do currículo é empregada na escola como um manual descritivo de ações a serem seguidas pelos professores, alunos e profissionais de ensino de forma mecânica, acrítica e destituída de sentido e significado.

O currículo acaba por não se configurar como um conjunto de orientações e hipóteses de trabalho, originários de um processo reflexivo por parte de todos que compõem o contexto escolar.

Quando analisamos a construção e a implementação do currículo, torna-se necessária uma atitude reflexiva permanente da própria comunidade sobre como o conhecimento escolar é construído (para quê, por quê, e o quê ensinar), não esquecendo jamais que ele é constituído pela interconexão entre conhecimentos científicos e sociais.

Entretanto, não é fácil estabelecer parâmetros de ação educativa que delimitem o trabalho docente, tanto na concepção do currículo como no desenho da própria matriz curricular.

Nesse sentido, há inúmeros desafios que precisam ser analisados. Dentre eles, destacamos a importância de os professores, nas suas práticas, ao elaborarem seus planejamentos de ensino, buscarem estabelecer:

- a interconexão dos objetivos;

- $\quad$ as interfaces dos conteúdos;

- a interação dos objetivos e os conteúdos por meio de atividades criativas, críticas e emancipatórias. 
O planejamento das atividades docentes e discentes não apenas passa pelas questões sociológicas, epistemológicas, psicológicas e didáticas, mas estas devem ser o centro de análise e reflexão pelo qual perpassará o Projeto Político Pedagógico da própria escola.

A integração do professor na sociedade, tendo clareza de por que e para que ensinar, o resgate dos conhecimentos prévios e a promoção de um ambiente educativo que favoreça a aquisição de novas idéias, o trabalho coletivo, as discussões epistemológicas e metodológicas nas diferentes áreas, tudo isso deve ser perseguido. Por isso, os objetivos deverão estar conectados com os conhecimentos dos alunos, da sociedade, das interfaces dos conteúdos e da concepção filosófica que delimita as condições naturais e sociais.

Em função do exposto, a planificação e a operacionalização dos conhecimentos escolares na matriz curricular deve propiciar uma dimensão vertical que implica a idéia de profundidade e complexidade crescente de conteúdo, e uma dimensão horizontal que estabelece a interação dos conhecimentos com as outras disciplinas/áreas. A idéia da implementação de práticas interdisciplinares deve desenhar, tecer e alinhavar a verticalidade e a horizontalidade da Matriz Curricular, para que os professores tenham claras as interfaces das disciplinas e as possíveis interrelações provenientes delas.

Assim, ao integrar o conhecimento escolar com as conceitos científicos, procedimentos, valores e atitudes sociais, há um movimento espiral, contínuo e permamente dos contéudos.

As idéias são consideradas fundamentais para compreender como os marcos curriculares inseridos nos PPPs (Projetos Políticos Pedagógicos) das escolas devem estar em consonância com a finalidade educativa, a filosofia da escola e, dentre outras coisas, com a interlocução dos conteúdos, objetivos e metodologia contemplados pelo trabalho docente por meio de atividades de ensino.

Contudo, muitas vezes os profissionais de ensino não se percebem como sujeitos do fazer educativo, deixando de constituir e construir suas próprias identidades pessoais e profissionais, gerando um espaço isolado e desconstituído de significados.

Ao analisarmos a escola, é preciso refletir sobre o contexto que a fundamenta e as relações que lá são estabelecidas. Sendo a escola um contexto social formado por pessoas, está embuída e vive das diferentes relações humanas que são estabelecidas por meio das inúmeras situações educativas.

Como a escola é um contexto social importante, urge analisarmos as inúmeras dimensões que devem ser valorizadas, respeitadas e trabalhadas, pois essas dimensões são frutos e se alimentam das relações estabelecidas entre as pessoas que compõem o ambiente escolar. 
AZEVEDO, M. A. R.; ANDRADE, M. F. R. O conhecimento em sala de aula: a organização do ensino numa perspectiva interdisciplinar

As dimensões são as seguintes:

- Social: relacionada com a comunidade escolar e todas as pessoas que fazem parte dela;

- Física: delimitação do aspecto geográfico, histórico, sociológico, antropológico e econômico;

- Temporal: enfoca a transitoriedade dos acontecimentos e a importância da herança cultural e da histórica acumulada;

- Psicológica/sociocultural: revela a interdepêndencia entre o contexto e as outras dimensões.

As relações sociais estabelecidas na escola delimitam muitas vezes os processos de ensino e aprendizagem, a própria filosofia da escola, o PPP que ela busca atingir, e as propostas educativas inerentes a ela e ao seu papel na sociedade.

Nesse sentido, quando configuramos a escola como um contexto social, o ambiente em sala de aula torna-se um espaço central para a aquisição de novos conhecimentos e a reestruturação de outros, uma vez que é estabelecida uma interação entre professores e alunos mediados por um processo dialógico/discurso.

A valorização da comunicação e o uso e a análise do discurso no processo dialógico tornam-se necessárias para o estabelecimento de espaços alternativos de saber ouvir, pensar, falar, enfim, de se comunicar, por meio de turnos alternativos, possibilitando a interlocução dos sujeitos, a análise do conteúdo do discurso e o tema a ser discutido e debatido, instrumentalizando professores e alunos para $\mathrm{o}$ ato de interagir de forma responsável e dinâmica.

Neste processo dialógico, as idéias, os pontos de vista, as formas de pensamento e as inúmeras experiências dos professores e alunos acabam oportunizando o exercício do pensar e da própria metacognição, gerando a aprendizagem por meio da mediação dos conflitos. A partilha dos significados pela linguagem gera, no contexto comunicativo, a colaboração mútua por meio de um trabalho que envolve tutoramento e grupos de colaboração.

Uma sala de aula que propicia um espaço interativo de diálogo em complexidade crescente potencializa o papel do professor e do aluno. O professor torna-se tutor do processo de construção dos conhecimentos e dos significados inerentes a eles e, em parceria com os alunos, problematiza o contexto escolar e social via grupos colaborativos e cooperativos. 
Ao desenvolver seu trabalho pedagógico, o professor deve, pois, promover atividades de ensino que instiguem os alunos a desenvolver suas potencialidades e a superar suas dificuldades, desafiando-os diariamente. O professor Manoel Oriosvaldo Moura, em seu artigo intitulado "A atividade de Ensino como Unidade Formadora", conceitua atividade como

um processo psicologicamente caracterizado por uma meta a que o processo se dirige (seu objeto), coincidindo sempre com o objeto que estimula o sujeito a executar esta atividade, isto é, o motivo [...] atividades que são principais em certo estágio da vida, determinando o desenvolvimento psíquico da criança, construindo, ainda, o critério de mudança de um estágio para o outro.

Destaca-se aqui o papel fundamental do planejamento de ensino e da ação responsável e competente do professor, haja vista que ele, ao dimensionar os conhecimentos escolares, deverá traduzi-los em atividades de ensino que encaminhem a ações carregadas de sentido, motivo e necessidades, exigindo da criança que ela se aproprie de uma série de conhecimentos e trabalhe com as suas funções psíquicas superiores via ação coletiva dos seus pares e nas interfaces das relações sociais e pessoais que permeiam os ambientes sociais.

Leontiev preocupou-se em especificar as atividades das crianças em cada idade, e a mudança de atividade estaria, para ele, na base da periodicidade do desenvolvimento da criança e determinaria as suas mudanças psicológicas, assim como sua consciência, suas relações com seu ambiente e com sua vida interior e exterior.

A atividade não deve, pois, ser entendida apenas pelo desenvolvimento de habilidades específicas, uma vez que consiste num processo metacognitivo por meio de uma situação intitulada "problemas de aprendizagem".

O problema de aprendizagem não deve ser, assim, confundido com um problema concreto a ser resolvido na prática. Ele é classificado dentro de uma organização de problemas que busca analisar os conceitos teóricos fundamentais a serem estruturados, organizados e trabalhados. Só a partir da análise do conceito teórico construído haverá a elaboração de um modo de ação generalizado que permitirá a abordagem dos problemas concretos.

Para que os problemas de aprendizagem possam caracterizar-se como atividade cognitiva, urge que a criança seja colocada num ambiente socialmente favorável para a aprendizagem, pois o resultado desse trabalho coletivo dependerá da ação, interação e participação ativa de cada um. 
Quando há cooperação nas atividades, os processos sociointeracionistas acabam por promover a organização interpessoal e intrapessoal de todos os envolvidos, e as funções psíquicas superiores das crianças acabam por se desenvolver nessas atividades de ensino.

A prática pedagógica interdisciplinar se apóia na intersecção da reorientação curricular e da formação docente caracterizada pela formação continuada dos professores, gerando o desenvolvimento pessoal, profissional e escolar.

A partir dessa idéia da reconstrução curricular e da formação docente contínua, significativa e reflexiva, impõe-se uma nova concepção do conhecimento; ele não pode ser considerado estático, pois é dinâmico e inacabado.

Assim, a dimensão dos conteúdos escolares na aprendizagem não tem fim em si mesma, mas tem significado quando esses conteúdos se tornam explicitadores e desveladores de uma realidade em que se pode intervir.

O currículo, a partir disso e numa perspectiva da gestão democrática da escola, torna-se diretamente relacionado ao coletivo da própria escola por meio do planejamento participativo.

No final da década de 1980, Paulo Freire (1989), o então Secretário da Educação do Município de São Paulo, com os professores formadores de algumas universidades e professores atuantes nas escolas municipais, construiu coletivamente uma proposta de implementação de ação interdisciplinar de grande valor educacional e social.

Nesse documento, a escola, ao assumir um projeto que implique a reestruturação curricular pela via da interdisciplinaridade e pela formação continuada de seus formadores, necessitaria assumir os seguintes pontos:

- delimitação dos papéis da comunidade, dos professores, dos alunos, da equipe diretiva;

- $\quad$ proposição de reflexões coletivas;

- recuperação do papel do professor;

- construção de conhecimentos com base na realidade;

- revisão do papel da escola;

- propiciar um ambiente educativo que retrate a produção, criação e erradicação de culturas;

- priorizar a construção coletiva. 
A escolha dos temas geradores é feita pelos professores com os alunos, por meio de discussões que levem em conta a interpretação e a inter-relação das situações, agrupando-as.

$\mathrm{Na}$ construção do programa curricular, o tema gerador tem a grande função de produzir mais e mais temas que deverão se entrelaçar, produzindo eixos temáticos que deverão contemplar:

- a visão de cada área do conhecimento;

- os fatores cognitivos, afetivos, sociais e psicológicos;

- a realidade e as situações significativas: fator principal na construção de um programa e seleção dos conteúdos;

- privilegiar a metodologia dialógica;

- o conhecimento acumulado e o conhecimento construído e reconstruído.

Com os eixos temáticos contemplados, os temas geradores necessitam ser trabalhados por meio de três grandes momentos:

\section{Primeiro:}

- perceber as relações existentes entre os temas;

- relacionar os conteúdos para compreender a realidade;

- desdobrar os conteúdos propostos em outros.

\section{Segundo:}

- selecionar os conteúdos, analisando-os de forma interativa;

- inter-relacionar conhecimentos, buscando conexões com a realidade proposta.

\section{Terceiro:}

- seriar os conteúdos, definindo a profundidade de sua abordagem em cada série/turma/módulo;

- registrar o programa a ser composto e recomposto;

- trabalhar de forma coletiva, contínua, sistemática e reflexiva. 
AZEVEDO, M. A. R.; ANDRADE, M. F. R. O conhecimento em sala de aula: a organização do ensino numa perspectiva interdisciplinar

Quanto ao processo avaliativo dessa proposta, devem-se levar em conta três aspectos fundamentais:

- função da avaliação no processo de ensino e de aprendizagem;

- os procedimentos de registro e acesso às informações;

- construção de um sistema avaliativo que contemple: discussões sobre as práticas avaliativas e o redimensionamento das formas de registro descritivo sobre a própria avaliação.

Assim, o papel dos temas geradores deve:

- $\quad$ enunciar situações problemáticas significativas;

- traduzir uma nova relação entre currículo, escola e comunidade;

- refletir sobre a realidade global e interdisciplinar;

- permitir ao mesmo tempo a compreensão do tema gerador a partir do conhecimento e da criação de novos conhecimentos;

- olhar de forma crítica e contextualizada a realidade local, geográfica, social e cultural.

Mas, para que os temas geradores tenham a função de privilegiar o pensar e o agir interdisciplinar, é necessário que o professor desenvolva, por um lado, uma atitude interdisciplinar que retrate uma metodologia dialógica, e, por outro, uma clareza que o leve a perceber e a trabalhar a interdisciplinaridade por meio de um princípio epistemológico.

Enfim, para encaminhar a ação pedagógica pela via da interdisciplinaridade, é necessário o estudo preliminar da realidade, a escolha de temas geradores e a construção do programa, selecionando e organizando os conhecimentos de forma dialética, dinâmica e contínua.

Nesse sentido, a idéia do trabalho interdisciplinar não passa pela unificação dos conhecimentos e saberes, mas pela busca incessante de troca entre eles, e é nessa construção do saber que a interdisciplinaridade se solidifica de fato, e não nos momentos posteriores, quando se buscam os saberes instituídos para organizá-los.

Assim, o professor realiza a transposição dos construtos/saberes e o aluno reconstrói e se apropria dos construtos/saberes de uma disciplina. Juntos, professor e aluno passam a estabelecer relações com outros saberes e com o próprio cotidiano, estabelecendo relações e construindo redes de conhecimentos. 
No processo progressivo da interação disciplinar, a interdisciplinaridade preconiza inicialmente um regresso aos fundamentos da disciplina, exigindo do professor que ele conheça, domine e construa, na sua própria área, um trabalho disciplinar de qualidade por meio da ação e da produção de conhecimento.

É necessário, para isso, um trabalho metodológico pautado no diálogo e na pesquisa, sendo o professor o próprio sujeito de sua ação docente como:

- programador de atividades;

- produtor de materiais pedagógicos alternativos;

- $\quad$ pesquisador e investigador do seu trabalho;

- problematizador da própria prática.

Essa prática interdisciplinar dialógica configura-se de forma dialética, emergindo a relação mudança-resistência à mudança ao próprio trabalho que está sendo vivenciado, exigindo transformações radicais nas relações de trabalho que contribuirão para a autonomia dos diferentes profissionais de ensino nas realidades escolares.

A implementação de uma ação interdisciplinar implica, então:

- $\quad$ perda da acomodação;

- lançar-se ao novo;

- reformulação da estrutura de ensino das diferentes disciplinas;

- transformação do trabalho pedagógico;

- novos encaminhamentos na área de formação de professores.

É pela vivência grupal que a interação entre as pessoas possibilitará o processo de desestruturação situacional do previsto, do possuído, do certo, do conhecido, para a busca de uma nova forma de se pensar e fazer ensino, permitindo a apropriação e o desenvolvimento do pensamento dialético por meio de novas sínteses e ações, do intercâmbio de informações, e de experiências vitais.

Assim, a construção de práticas pedagógicas interdisciplinares passa pelos seguintes aspectos:

- professor resgatando os aspectos da reconstrução profissional e pessoal; 
AZEVEDO, M. A. R.; ANDRADE, M. F. R. O conhecimento em sala de aula: a organização do ensino numa perspectiva interdisciplinar

- construção de eixos temáticos que nortearão o trabalho pedagógico no aspecto teórico-prático;

- eixos temáticos articulando os diferentes saberes pela interconexão dos professores com os outros;

- especificidade de cada ciência resgatando seus construtos;

- construção de novos construtos/saberes que retratem a gênese de novos conhecimentos, frutos do trabalho que prima pela diferença e criação;

- profissionais competentes quando aprofundarem e operacionalizarem pressupostos epistemológicos e metodológicos na relação profissional, na realidade escolar e com o conhecimento;

- interconexões entre homem-ciência-mundo num pano de fundo científico que abordará a educação em novas oportunidades de teorizar a ação;

- cursos de formação continuada tendo a clareza sobre a função formativa e as reais necessidades formativas dos sujeitos envolvidos, construindo e exigindo uma postura crítico-reflexiva das práticas exercidas dos professores, possibilitando a reconstrução sistemática da identidade do professor.

A interdisciplinaridade é vista, então, como instrumento que possibilite à escola tornar-se um lugar onde se produza coletiva e criticamente o conhecimento, desacomodando, para isso, pessoas, exigindo dos professores estudo teóricoprático maciço dessa temática e o investimento profundo do desenvolvimento profissional dos educadores para atuar com competência e discernimento perante as incertezas e incongruências do próprio sistema educacional brasileiro.

\section{Conclusões}

A interdisciplinaridade não é uma idéia nova. A civilização ocidental sempre buscou a mutualidade dos saberes mesmo sob a égide de outros tipos de observação, como no âmbito da história da filosofia, por exemplo, buscando uma possível compreensão da totalidade.

A interdisciplinaridade não deve ser concebida como o único caminho para 
que sejam resolvidos os problemas da educação, mas sua implementação no sistema educacional é de suma importância, uma vez que por ela perpassam, além das questões metodológicas, as de cunho político, ético e econômico no ensino.

A efetivação de um trabalho interdisciplinar, tanto em pesquisa quanto em sala de aula, vai além da integração de diferentes áreas, pois a interdisciplinaridade pressupõe a construção incessante das relações entre docentes, que ultrapassa a simples unificação de saberes. Para isso, faz-se necessário o real profissionalismo do professor, ou seja, a competência em sua área de atuação, ao método de seu saber (disciplina ou especialidade).

Interdisciplinaridade é um princípio epistemológico e uma atitude metodológica. Na prática, o primeiro refere-se à construção do conhecimento de forma racional, e na segunda há uma situação de comunicação, de parceria entre os diferentes saberes permeada por um trabalho metodológico inovador.

Aótica da interdisciplinaridade fundamenta-se na construção e reconstrução de saberes, possibilitando um vasto espaço para o conhecimento e aprimoramento dos próprios sujeitos. É uma forma sempre atual de contextualização dos saberes, pois são consideradas as necessidades e exigências do momento, mas sempre alicerçadas nos conhecimentos já adquiridos e significados.

Nesse sentido, a interdisciplinaridade não trabalha o conhecimento de maneira globalizante, a fim de unificar os saberes, mas busca promover interconexões entre os saberes, tanto entre professores e seus pares quanto entre professores e alunos, trabalhando o conhecimento de forma problematizadora e estabelecendo relações entre as diferentes ciências, o cotidiano escolar e a realidade social e histórica em que os sujeitos estão envolvidos.

\section{REFERÊNCIAS}

FAZENDA, I. C. A. Práticas interdisciplinares na escola. 2. ed. São Paulo: Cortez, 1993.

. Integração e interdisciplinaridade no ensino brasileiro: efetivação ou ideologia. 3. ed. São Paulo: Loyola, 1993.

FREIRE, P. Pedagogia da autonomia: saberes necessários à prática educativa. São Paulo: Paz e Terra, 1996.

Ação pedagógica da escola pela via da interdisciplinaridade. São Paulo:

Secretaria da Educação de São Paulo. Cadernos de Formação, I, II e III, 1989. 
AZEVEDO, M. A. R.; ANDRADE, M. F. R. O conhecimento em sala de aula: a organização do ensino numa perspectiva interdisciplinar

MANZO, A. J. Manual para la preparación de monografías: una guía para presentear informes y tesis. Buenos Aires: Humanistas, 1971.

SCHON, D. The reflective practitioner: how professionals think in action. San Francisco: Jossey-Bass, 1983.

TOMAZETTI, E. Estrutura conceitual para uma abordagem do significado da interdisciplinaridade: um estudo crítico. UFSM, n. 10, p. 1-43, 1998.

Texto recebido em 18 out. 2006 Texto aprovado em 29 jan. 2007 